\title{
Mandibular Overdentures Retained by Two Implants: 10-Year Results from a Crossover Clinical Trial Comparing Ball-Socket and Bar-Clip Attachments
}

\author{
Marco Cune, DDS, PhDa/Mark Burgers, DDS ${ }^{b} /$ Frits van Kampen, DDS, $\mathrm{PhD}^{\mathrm{c}} /$ \\ Cornelis de Putter, DDS, $\mathrm{PhD}^{\mathrm{d}} /$ Andries van der Bilt, $\mathrm{PhD}^{\mathrm{e}}$
}

\begin{abstract}
Purpose: The aim of this study was to evaluate patient satisfaction and clinical and prosthetic outcomes of two-implant mandibular overdenture treatment with different attachment types after 10 years of function. Materials and Methods: In a crossover clinical trial, 18 edentulous subjects with complaints regarding their mandibular dentures received two implants and a new denture with magnet, ball-socket, or barclip attachments that were applied in a random order. At the end of the experiment, the attachment type of their choosing was fitted in the overdenture. After 10 years, 7 subjects with a ball-socket and 7 subjects with a bar-clip attachment were available for evaluation. The same questionnaire from 10 years before was completed, and subjects were asked to express their overall appreciation of their dentures on a visual analog scale (VAS). Six scales of denture complaints were constructed. Mean scale and VAS scores between initial evaluation and after 10 years were compared. In addition, marginal probing depths, Bleeding Index, and radiographic marginal bone loss were assessed. Results: There was no marked difference in satisfaction between subjects with ball-socket- and bar-clip-retained two-implant mandibular overdentures at initial evaluation and after 10 years of function. Conclusion: Patients' appreciation of their implant-retained denture was and remained high over time. Clinical parameters revealed healthy mucosal conditions and stable marginal bone levels, determined radiographically. Probing depths around implants provided with ballsocket attachments were slightly shallower than those with bar-clip attachments after 10 years of function $(P<.05)$. Int $J$ Prosthodont 2010;23:310-317.
\end{abstract}

\footnotetext{
aprofessor, Department of Fixed and Removable Prosthodontics, Center for Dentistry and Oral Hygiene, University Medical Center Groningen, Groningen, The Netherlands; Department of OralMaxillofacial Surgery, Prosthodontics and Special Dental Care, St. Antonius Hospital, Nieuwegein, The Netherlands.

${ }^{b}$ Research Associate, Department of Oral-Maxillofacial Surgery, Prosthodontics and Special Dental Care, University Medical Center Utrecht, Utrecht, The Netherlands; Marine Training Command Dental Center, Doorn, The Netherlands.

${ }^{c}$ Research Associate, Department of Oral-Maxillofacial Surgery, Prosthodontics and Special Dental Care, University Medical Center Utrecht, Utrecht, The Netherlands; Central Military Hospital, Utrecht, The Netherlands.

'Professor, Department of Oral-Maxillofacial Surgery, Prosthodontics and Special Dental Care, University Medical Center Utrecht, Utrecht, The Netherlands.

${ }^{e}$ Associate Professor, Department of Oral-Maxillofacial Surgery, Prosthodontics and Special Dental Care, University Medical Center Utrecht, Utrecht, The Netherlands.
}

Correspondence to: Prof Dr M.S. Cune, UMC Groningen/Center for Dentistry and Oral Hygiene, Department of Fixed and Removable Prosthodontics, Gebouw 3212, Kamer 206, A. Deusinglaan 1, 9713 AV Groningen, The Netherlands. Fax: +31 (0) 50-363 2654. Email:m.s.cune@med.umcg.nl
L ack of retention and stability of the mandibular denture is a common problem among edentulous denture wearers. Initially, treatment with endosseous implants consisted of the placement of four to six implants in combination with a fixed prosthesis. It proved quite successful. ${ }^{1}$ Implant overdenture treatment was adopted later, and long-term clinical results were shown to be excellent as well. ${ }^{2}$ Over the years, much experience has been gained regarding the benefits of two implant-retained mandibular overdentures. It was demonstrated convincingly in well-designed clinical trials that two-implant overdentures provide superior function and satisfaction when compared to conventional dentures and preprosthetic surgery in patients with persistent denture complaints. ${ }^{3-10}$ By some, it is even considered to be the standard of care in cases of mandibular edentulism. ${ }^{11}$ Others point out that the benefits in masticatory performance are limited to patients with an atrophic mandible who experience difficulties in adapting to complete conventional dentures and that initial treatment costs are higher. ${ }^{12,13}$ Using more than 
two implants generally has no obvious clinical, functional, and subjective advantages when they are used to support an overdenture, although specific indications for the use of more than two implants may apply. ${ }^{14-16}$ Favorable 1-year clinical and subjective results on the application of a single implant in the symphysis region as compared to two implants have been reported, ${ }^{17}$ but a lack of evidence to support this treatment option has also been recognized. ${ }^{18}$ There appears to be little difference in oral function and patient satisfaction between mainly tissue-supported and implant-supported mandibular overdentures, and the same applies to removable versus nonremovable prosthetic appliances. ${ }^{8,19-24}$ In addition, treatment with fixed dentures has been shown to generate significantly more costs with respect to prosthetic maintenance compared to implant overdenture treatment, ${ }^{25,26}$ although others state that the initial costs of treatment need not be different. ${ }^{27}$

When providing a removable two implant-retained mandibular overdenture, various attachment types are available to the clinician: splinting the implants by means of a bar construction or loading them separately through ball-socket attachments, telescopic crown attachments, or magnets. In addition, several variations of conceptionally similar attachment systems (eg, barclip attachments with round bars versus egg- or Ushaped Dolder bars and different shapes of ball-socket attachments with gold matrices versus $\mathrm{O}$-ring matrices) may be used.

The ultimate choice of attachment type should be based on scientific evidence related to the clinical performance of the implants and attachments, on objective oral function, and on the patients' appreciation of treatment. The initial and eventual costs of maintenance and repairs must also be taken into account. Such evidence should come from clinical trials comparing restorative options in a single study population, preferably with a long observation period. Unfortunately, studies that address all of these aspects are quite scarce. From a systematic review on patient- and dentist-mediated outcome measures of treatment modalities for the edentulous mandible, a lack of evidence for a single, universally superior treatment modality was noted. The author stipulates the need for better designed, long-term studies to further explore the benefits of each treatment intervention for the edentulous mandible. ${ }^{28}$

In a short-term crossover clinical trial (withinsubject comparison) by the present group of authors, the hypothesis that the greater retention and stability of a two implant-retained mandibular overdenture yields higher patient satisfaction and will improve various parameters of masticatory function was tested in 18 subjects. The variation in retention and stability was modeled by applying bar-clip, ball-socket, and magnet attachments in a random order. The subjects exhibited a higher maximum occlusal force and chewed more efficiently after implant treatment, irrespective of the attachment type used. ${ }^{7,29,30}$ No difference in oral functions between the three attachment types was observed, although the degree of retention varied considerably. ${ }^{31}$ Subjects strongly preferred bar-clip and ball-socket attachments over magnet attachments, but their preference could not be predicted on the basis of baseline observations. ${ }^{32}$ The initial experiment took 1 year to complete for each subject.

The aim of the present study was to compare these initial measures of patient satisfaction and clinical performance of two implant-retained mandibular overdentures with data obtained after 10 years under the null hypothesis that they would be similar. Different attachment types were compared.

\section{Materials and Methods}

\section{Patient Population and Treatment Protocol}

Eighteen edentulous subjects from the Royal Dutch Army and Air Force participated in this randomized crossover clinical trial. They were referred to the Centre for Special Dental Care of the Central Military Hospital in Utrecht, The Netherlands, because of functional complaints regarding their mandibular denture. The group consisted of 1 woman and 17 men ranging in age from 33 to 56 years. All subjects were healthy and fit for military service. The bone height in the interforaminal region exceeded $15 \mathrm{~mm}$. Two oral implants (Frialit2, Friadent) were placed according to a standardized surgical protocol published elsewhere. ${ }^{30}$

Prosthodontic procedures started 1 week after stage-one surgery. New, conventional maxillary and mandibular dentures were made. The dentures were made in centric occlusion with balanced articulation and with anatomically shaped acrylic teeth (Bonartic, Ivoclar). In each quadrant, one premolar and two molars were used. One week following stage-two surgery, the healing collars were removed and pickup impression posts were placed at the implant level. A master cast was poured and one of three different attachment types was incorporated in the existing, newly fabricated denture: magnet (Dyna magnet ES, type extra strong, Dyna Dental Engineering), bar-clip (round bar in conjunction with a metal omega-shaped IMZ clip, Friadent), and ball-socket (Ball-socket attachment, Frialit-2, Friadent). The mean resistances to vertical dislodgement were approximately 8,31 , and $30 \mathrm{~N}$, respectively. ${ }^{31}$

The attachment type was changed after 3 and 6 months, respectively, in a random order. Because the same denture base was used, similar occlusion and articulation, vertical height, and denture base extension 


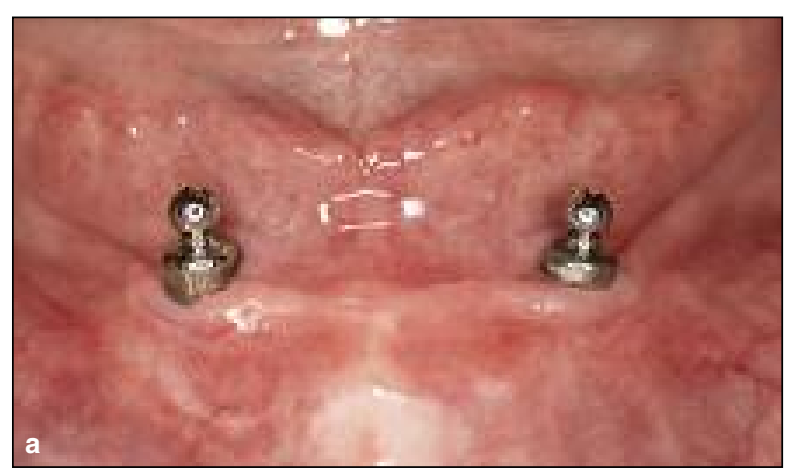

Figs 1a and 1b Examples of a (a) ball-socket attachment and

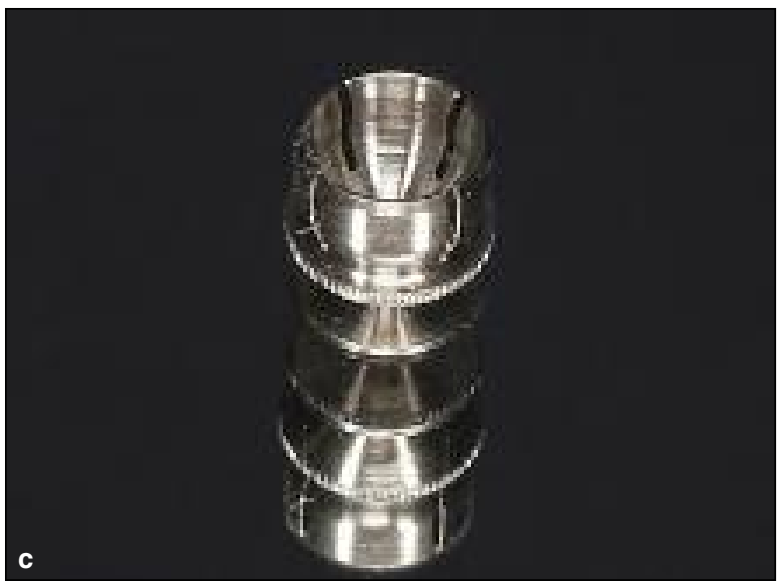

Figs 1c and 1d Clip used for the (c) ball-socket attachment and (d) bar-clip attachment.

was maintained throughout the course of the trial. ${ }^{31} \mathrm{At}$ the end of the initial study, approximately after 1 year, the dentures were fitted with the attachment type of the subjects' choosing. The subjects were referred back to their own dentist for regular maintenance and aftercare. These subjects were recalled and reexamined after 10 years.

Data were gathered prior to implant treatment (old denture), just prior to stage-two surgery (new denture without attachments, after 3 months of function), after 3 months of function with each of the attachment types (overdenture), and after 10 years.

After 10 years, 4 of the initial 18 subjects were lost to follow-up. They left military service and their current whereabouts could not be retrieved. One of these subjects was the only subject who, after the initial experiment, had chosen a magnet-retained mandibular overdenture. It is important to note that in the present report, results are reported on the 14 subjects with a complete data set only. Ball-socket and bar-clip attachments were evenly distributed among the current population. Consequently, two subgroups existed: 7 subjects with ball-socket and 7 subjects with bar-clip attachments, all males (Fig 1).

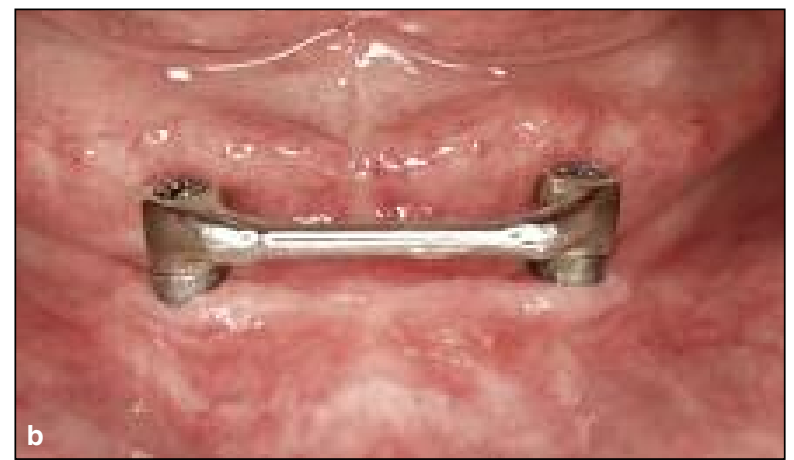

(b) bar-clip attachment.

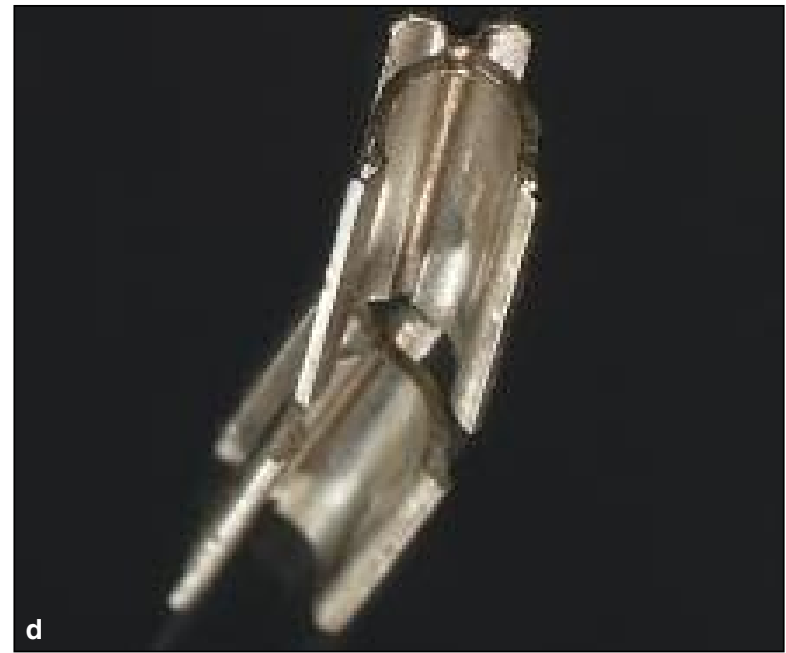

\section{Patient Satisfaction}

A questionnaire consisting of 54 questions with a fourpoint scale was developed to gauge patient satisfaction $(0=$ no complaints, $1=$ minor complaints, $2=$ moderate problems, and $3=$ severe complaints). Subsequently, six scales were constructed (Table 1). The reliability of the constructed scales, measured by calculating their internal consistency and expressed as Cronbach alpha, was satisfactory, showed little variation, and varied between 0.76 and 0.89 , depending on the study and the scale. ${ }^{33}$

In addition, the subjects were asked to grade their dentures (overall satisfaction) on a visual analog scale (VAS) ranging from 0 to 100 . The subjects were requested to place a dot on a line $100-\mathrm{mm}$ long $(0$ on one end, 100 on the other). The distance from 0 represented the degree of overall satisfaction. The higher the score, the more satisfied the subject was.

The initial mean scale scores obtained for the final attachment chosen were compared with those after 10 years of function. 
Table 1 Constructed Scales ${ }^{32}$

- Maxillary denture ( $n=9$ items): eg, "the maxillary denture loosens while eating," "the maxillary denture loosens while speaking," "the maxillary denture hurts while eating hard food types," "burning sensation underneath the maxillary denture"

- Mandibular denture ( $n=9$ items): eg, "the mandibular denture loosens while eating," "the mandibular denture loosens while speaking,"

"the mandibular denture hurts while eating hard food types," "burning sensation underneath the mandibular denture"

- General ( $n=18$ items): eg, "dry mouth," "chewing is hard," "teeth and molars from maxillary and mandibular denture make contact while speaking," "nervousness because of the dentures"

- Physiognomy ( $n=3$ items): "the lip has fallen in," "the cheeks have fallen in," "the mouth has fallen in"

- Neutral space ( $n=4$ items): "the tongue has too little space," “I bite my tongue," "I bite my cheeks," "I bite my lip"

- Esthetics ( $n=11$ items): eg, "the teeth are too large," "the teeth are too white," "you don't see enough teeth," "the teeth are not positioned the way I would like them to be"

\section{Clinical Parameters}

The health of the peri-implant mucosa was assessed after marginal probing with a periodontal probe $\mathrm{Hu}-$ Friedy) at four locations, as expressed by a Bleeding Index in which $0=$ healthy with no signs of inflammation or inflammation-related symptoms; $1=$ slight inflammation, no bleeding on marginal probing, no swelling; 2 =bleeding on marginal probing, redness or swelling; and $3=$ spontaneous bleeding, swelling, redness, or necrosis. ${ }^{34}$

Fifteen seconds were allowed for bleeding to occur after probing. Probing depths were measured at four locations using gentle probing to measure the distance from the marginal peri-implant mucosa to the deepest point of the peri-implant sulcus. The measurements for the Bleeding Index and probing depth after 10 years of function were compared with those obtained at initial evaluation when a similar attachment type was in situ. Intraoral radiographs made after implant placement and after 10 years of function were compared. The mesial and distal marginal bone levels were assessed using the edge of the implant as a reference point, as previously described in detail. ${ }^{35,36}$ Clinical and radiographic measurements for all sites and for both implants were grouped and subsequently averaged for all parameters.

\section{Prosthetic Outcome}

Subjects were interviewed with respect to the occurrence of complications, major repairs, or renewal of their dentures over the past 10 years.

\section{Statistical Analysis}

Mean scale scores (patient satisfaction), probing depths, and marginal bone levels (clinical parameters) were compared by means of paired $t$ tests. For comparison of Bleeding Index scores, the Wilcoxon signed ranks test was used. All analyses were performed using a standard statistical program (SPSS version 15.0 for Windows, SPSS).
Table 2 Mean Scale and VAS Scores (SD) at Initial Evaluation and After 10 Years ( $n=14$ Subjects)

\begin{tabular}{lccc}
\hline Scale & $\begin{array}{c}\text { Initial } \\
\text { evaluation }\end{array}$ & $\begin{array}{c}\text { 10-year } \\
\text { evaluation }\end{array}$ & $P^{*}$ \\
\hline Maxillary denture & $0.4(0.4)$ & $0.2(0.2)$ & NS \\
Mandibular denture & $0.2(0.2)$ & $0.3(0.4)$ & NS \\
General & $0.2(0.3)$ & $0.2(0.3)$ & NS \\
Physiognomy & $0.1(0.3)$ & $0.3(0.5)$ & NS \\
Neutral space & $0.2(0.3)$ & $0.1(0.2)$ & NS \\
Esthetics & $0.1(0.1)$ & $0.2(0.3)$ & NS \\
VAS score & $88.7(11.4)$ & $86.6(17.5)$ & NS \\
\hline
\end{tabular}

$\mathrm{SD}=$ standard deviation; NS = not significant

${ }^{*}$ Paired $t$ test.

Scale scores (range 0 to 3 ): $0=$ no complaints, $1=$ little complaints, $2=$ moderate complaints, $3=$ severe complaints. VAS scores (range 0 to 100): $0=$ very dissatisfied, $100=$ very satisfied.

\section{Results}

A comparison of the initial scale and VAS scores, as well as clinical and radiographic measures of the dropouts with those who could be reevaluated after 10 years, revealed no significant differences.

\section{Patient Satisfaction}

The differences in mean scale and VAS scores for subjects with ball-socket $(n=7)$ and bar-clip attachments $(n=7)$ did not reach a statistically significant level at the initial nor at the 10-year evaluation. The scores were grouped and are presented in Table 2 . Therefore, the null hypothesis that there would be no statistical difference in scale and VAS scores between initial evaluation and observations after 10 years could not be rejected.

\section{Clinical Parameters}

None of the 14 subjects reported any major complications such as implant loss. No additional surgical interventions were reported. Healthy soft tissues were encountered, with no statistically significant differences between initial and 10-year evaluations or among the two attachment types at either moment in time. Mean probing depths were $2.3 \pm 0.8 \mathrm{~mm}$ and $2.6 \pm 0.7 \mathrm{~mm}$ 
Table 3 Mean Scores (SD) for Probing Depth and Marginal Bone Level and Distribution of Bleeding Index Values at Initial Evaluation and After 10 Years ( $n=14$ Subjects)

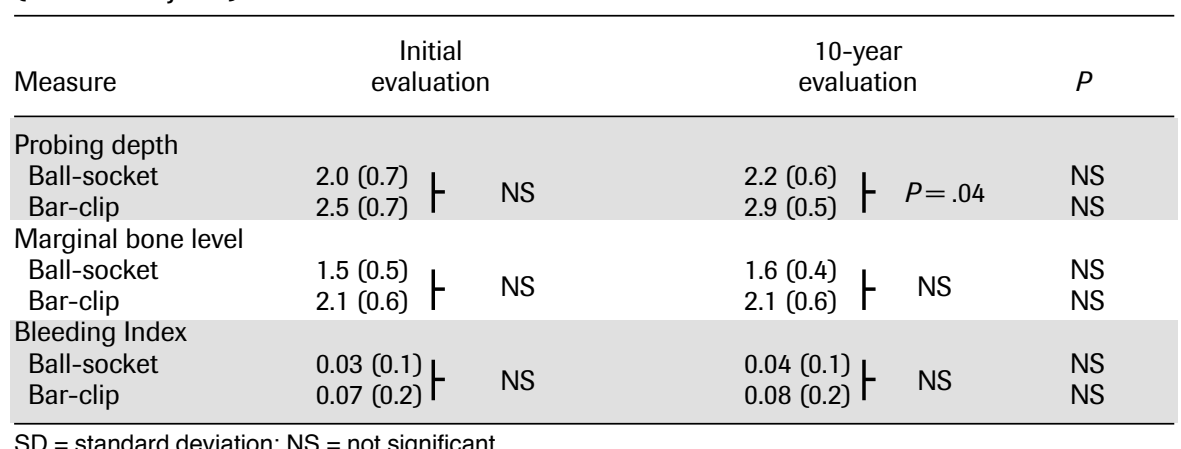

Table 4 Major Prosthetic Events as Reported by the Patient

\begin{tabular}{|c|c|c|c|c|c|c|c|}
\hline Patient & $\begin{array}{l}\text { Attach- } \\
\text { ment } \\
\text { type }\end{array}$ & $\begin{array}{c}\text { New } \\
\text { maxillary } \\
\text { denture }\end{array}$ & $\begin{array}{c}\text { New } \\
\text { mandibular } \\
\text { denture }\end{array}$ & $\begin{array}{c}\text { Relining } \\
\text { maxillary } \\
\text { denture }\end{array}$ & $\begin{array}{l}\text { Relining } \\
\text { mandibular } \\
\text { denture }\end{array}$ & $\begin{array}{c}\text { Clip } \\
\text { replacement }\end{array}$ & Complications \\
\hline 1 & ball & 1 & 1 & 1 & & & \\
\hline 2 & ball & & & & 1 & & Broken mandibular and maxillary denture $(n=1)$ \\
\hline 3 & bar & 1 & 1 & & & 1 & Broken mandibular denture $(n=3$, now metal reinforced $)$ \\
\hline 4 & ball & & & 3 & 2 & & \\
\hline 5 & bar & 1 & 1 & & & & \\
\hline 6 & ball & 1 & 1 & & & & \\
\hline 7 & bar & 1 & 1 & 1 & & & \\
\hline 8 & bar & & & & & & \\
\hline 9 & ball & 1 & 1 & & & & Loosening of ball-attachment matrix (several times) \\
\hline 10 & bar & & & & & & \\
\hline 11 & bar & 1 & 1 & & & & \\
\hline 12 & ball & & & & & & \\
\hline 13 & bar & 1 & 1 & 1 & & & \\
\hline 14 & ball & & & & & 1 & \\
\hline
\end{tabular}

at the initial and 10-year evaluation, respectively (not significant). The mean probing depth at 10 years around implants with a ball-socket attachment was shallower than around implants provided with a bar-clip attachment $(P<.05)$.

The marginal bone levels remained quite stable between implant placement and after 10 years of function (1.8 $\pm 0.6 \mathrm{~mm}$ versus $1.9 \pm 0.6 \mathrm{~mm}$, respectively). The difference between ball-socket and bar-clip attachments was not statistically significant (Table 3).

\section{Prosthetic Outcome}

No change of attachment type occurred. The major prosthetic events are presented in Table 4. A new set of dentures had been made in 8 of 14 subjects during the 10-year evaluation period. The data set does not allow detailed and statistical comparison between ballclip and bar-socket attachments with respect to prosthetic maintenance, but only a slight difference in the occurrence of major prosthetic events seemed apparent between the two attachment types (Table 4).

\section{Discussion}

In The Netherlands, a two implant-retained mandibular overdenture is generally the treatment of choice in the case of mandibular edentulism and denture complaints. It has been included in the national health insurance scheme for over 20 years, whereas a fixed implant-supported prosthesis is not. The out-of-pocket expenses for initial surgical and prosthetic treatment, as well as for long-term maintenance, are low. . $^{37,38}$

There is ample information available from various research groups to indicate the effectiveness of implantretained mandibular overdentures when compared to conventional dentures, both with respect to patients' appreciation of treatment and improvement in oral function, although the impact on general health-related quality of life has not been shown convincingly to date. ${ }^{3-10,12,32,39,40}$ Also, detailed studies comparing different treatment choices in mandibular implant overdenture treatment are relatively scarce. ${ }^{28}$ Long evaluation periods are important to establish whether the initial enthusiasm frequently associated with new 
treatment strategies proves justified in the long run. In the present study, subjects who underwent two-implant mandibular overdenture treatment with ball-socket and bar-clip attachments were reevaluated after 10 years and compared. The results from clinical and subjective outcome measures are reported.

Subjects were and remained satisfied with different aspects of their two implant-retained mandibular overdenture fit with the attachment type of their choice, even after 10 years (Table 2). This is in agreement with the results from other long-term prospective clinical trials in a comparable edentulous Dutch population ${ }^{5,6,8}$; they used bar-clip attachments only. As in the present study, Naert et al ${ }^{41}$ could not demonstrate a difference in patients' appreciation between mandibular implants provided with a bar-clip or with a ball-socket attachment (O-ring) in a Belgian population after 10 years. However, Timmerman et $\mathrm{al}^{19}$ reported a statistically significant drop in appreciation with ball-socket attachments, whereas the opinion of patients with barclip attachments remained stable after 8 years. The latter is in contrast to the observations in the present study. One can only guess as to an explanation for the different findings in these two studies. Patients treated in the study population of Timmerman et al ${ }^{19}$ were enrolled in a more strict protocol of aftercare than the subjects in the present study, and a fair amount of maintenance was required and provided by them. It is interesting to note that the total number of visits and total treatment time required for maintenance does not seem markedly different between patients from their ball-socket and bar-clip groups. ${ }^{42}$

Results from other clinical trials with a shorter observation period in which ball-socket and bar-clip attachments were compared with respect to the required amount of maintenance appear contradictory. The design of the ball attachment and matrix and materials used in mandibular overdenture treatment seem to be an important determinant. ${ }^{42}$ The use of a two-piece ball-abutment, ${ }^{43} \mathrm{O}$-ring matrices, ${ }^{41}$ and matrices with a so-called "c-spring" 44,45 have been associated with relatively high maintenance when compared to bar-clip attachments and some have even been taken off the market. On the other hand, Gotfredsen and Holm ${ }^{46}$ reported favorably on one-piece ball-socket Dalbo attachments with a golden matrix compared to bar-clip attachments after 5 years. In another study, the amount of maintenance between ball-socket and bar-clip attachments was not statistically different, although a slight superiority of the rigid bar was suggested by the authors. ${ }^{47}$ On a more general note, it can be stated that new types of attachment systems are introduced to the market on a regular basis. Some appear to function reasonably well (eg, Locator abutments) but lack longterm evaluation. ${ }^{48}$
It was felt that registration of the occurrence of minor prosthetic revisions over a 10-year period (eg, relieving of pressure points, activation of matrices) could not be done in a reliable manner by means of an interview. As a consequence, the subjective documentation of repairs and revisions may have led to unintentional underreporting by the subjects. Because they were referred to their general dentist after the conclusion of the initial experiment and a strict maintenance program with yearly recall visits was not always offered, the extent of the actual provided prosthodontic maintenance may have been relatively low as well. The former issues should be taken into consideration when interpreting the observations on prosthodontic maintenance reported in this study.

A general impression of the major prosthodontic events is presented in Table 4. Eight of 14 subjects received a new denture during the 10-year time span, but the type of attachment remained unchanged. The number of remakes seems rather high when compared to a study by Visser et al ${ }^{49}$ covering a similar evaluation period. Well-defined criteria that determine when a denture should be remade are not available. Replacement dentures are not only provided when they no longer fit well or provide adequate function and when repairs and revisions are not indicated or possible. External circumstances such as the prospect of changing health insurance may also play a role. The latter was the case during the observation period of this study on several instances. It is important to note that in the present study, a new denture was provided for several patients just before the subject left the military as a service to the patient and not necessarily because the denture needed replacement at that particular time, but possibly in the near future. In a more general context, standardized criteria to document prosthodontic success or failure and terms and criteria for maintenance have not been available or uniformly applied in the literature, although suggestions have been made. ${ }^{50,51}$ As such, reports and data from different centers on the amount of maintenance, particularly long-term ones, are hard to compare with one another, although attempts again have been made. ${ }^{52}$ Comparisons with the findings from the present study should be made prudently and with care.

The health of the peri-implant mucosa in this study was monitored by means of probing and the assessment of a Bleeding Index. The reliability of such parameters in measuring peri-implant health around implants in the edentulous mandible has been questioned. ${ }^{53}$ However, from the results of a systematic review on clinical, radiologic, and biochemical parameters used to monitor periimplant health, their ongoing use for the early diagnosis of peri-implant disease was recommended and is generally accepted. ${ }^{54-56}$ Clinical and radiographic data in 
the present study revealed healthy, stable intraoral conditions, and the absence of major comparative changes in marginal bone level forms an important and favorable outcome measure reflecting the peri-implant condition. ${ }^{53}$ In light of the fact that no major changes in marginal bone levels were observed between baseline and after 10 years of function, measurements at intervening time points would have been interesting but are not missed critically.

The favorable clinical and radiographic findings are in agreement with other long-term observational studies and clinical trials. ${ }^{5,40,57} \mathrm{~A}$ difference in peri-implant health between implants supporting bar-clip- and ball-socket-retained two-implant mandibular overdentures was not noted in several clinical trials lasting 5 to 10 years. ${ }^{46,57,58}$ In the present study, however, somewhat shallower probing depths were observed around ball-socket attachments when compared to the bar-clip attachments after 10 years.

\section{Conclusion}

There was no marked difference in patient satisfaction between subjects with ball-socket- and bar-clip-retained two-implant mandibular overdentures at initial evaluation and after 10 years of function. Furthermore, patients' appreciation for their two implant-retained mandibular overdenture was and remained high at initial observation and after a decade. Healthy and stable clinical and radiographic conditions were seen after 10 years of function, with slightly shallower probing depths around implants that were provided with ball-socket attachments.

\section{References}

1. Attard NJ, Zarb GA. Long-term treatment outcomes in edentulous patients with implant-fixed prostheses: The Toronto study. Int J Prosthodont 2004;17:417-424.

2. Attard NJ, Zarb GA. Long-term treatment outcomes in edentulous patients with implant overdentures: The Toronto study. Int J Prosthodont 2004;17:425-433.

3. Hobkirk JA, Abdel-Latif HH, Howlett J, Welfare R, Moles DR. Prosthetic treatment time and satisfaction of edentulous patients treated with conventional or implant-supported complete mandibular dentures: A case-control study (part 1). Int J Prosthodont 2008;21:489-495.

4. Hobkirk JA, Abdel-Latif HH, Howlett J, Welfare R, Moles DR. Prosthetic treatment time and satisfaction of edentulous patients treated with conventional or implant-stabilized complete mandibular dentures: A case-control study (part 2). Int J Prosthodont 2009; 22:13-19.

5. Meijer HJ, Raghoebar GM, Van't Hof MA, Visser A. A controlled clinical trial of implant-retained mandibular overdentures: 10 years' results of clinical aspects and aftercare of IMZ implants and Brånemark implants. Clin Oral Implants Res 2004;15:421-427.
6. Raghoebar GM, Meijer HJ, van 't Hof M, Stegenga B, Vissink A. $A$ randomized prospective clinical trial on the effectiveness of three treatment modalities for patients with lower denture problems. A 10 year follow-up study on patient satisfaction. Int J Oral Maxillofac Surg 2003;32:498-503.

7. van der Bilt A, van Kampen FM, Cune MS. Masticatory function with mandibular implant-supported overdentures fitted with different attachment types. Eur J Oral Sci 2006;114:191-196.

8. Meijer HJ, Raghoebar GM, Batenburg RH, Visser A, Vissink A. Mandibular overdentures supported by two or four endosseous implants: A 10-year clinical trial. Clin Oral Implants Res 2009; 20:722-728.

9. Emami E, Heydecke G, Rompré PH, de Grandmont P, Feine JS. Impact of implant support for mandibular dentures on satisfaction, oral and general health-related quality of life: a meta-analysis of randomized-controlled trials. Clin Oral Implants Res 2009;20:533-544.

10. Meijer HJ, Raghoebar GM, Batenburg RH, Vissink A. Mandibular overdentures supported by two Brånemark, IMZ or ITI implants: A ten-year prospective randomized study. J Clin Periodontol 2009; 36:799-806.

11. Feine JS, Carlsson GE, Awad MA, et al. The McGill Consensus Statement on Overdentures. Montreal, Quebec, Canada. May 2425, 2002. Int J Prosthodont 2002;15:413-414.

12. Fueki K, Kimoto K, Ogawa T, Garrett NR. Effect of implant-supported or retained dentures on masticatory performance: A systematic review. J Prosthet Dent 2007;98:470-477.

13. Takanashi Y, Penrod JR, Lund JP, Feine JS. A cost comparison of mandibular two-implant overdenture and conventional denture treatment. Int J Prosthodont 2004;17:181-186.

14. Batenburg RH, Meijer HJ, Raghoebar GM, Vissink A. Treatment concept for mandibular overdentures supported by endosseous implants: A literature review. Int J Oral Maxillofac Implants 1998; 13:539-545.

15. Klemetti E. Is there a certain number of implants needed to retain an overdenture? J Oral Rehabil 2008;35(suppl 1):80-84.

16. Meijer HJ, Raghoebar GM, Batenburg RH, Visser A, Vissink A. Mandibular overdentures supported by two or four endosseous implants: A 10-year clinical trial. Clin Oral Implants Res 2009;20: 722-728.

17. Walton JN, Glick N, MacEntee MI. A randomized clinical trial comparing patient satisfaction and prosthetic outcomes with mandibular overdentures retained by one or two implants. Int J Prosthodont 2009;22:331-339.

18. Alsabeeha N, Payne AG, De Silva RK, Swain MV. Mandibular single-implant overdentures: A review with surgical and prosthodontic perspectives of a novel approach. Clin Oral Implants Res 2009;20:356-365.

19. Timmerman R, Stoker GT, Wismeijer D, Oosterveld P, Vermeeren $\mathrm{JI}$, van Waas MA. An eight-year follow-up to a randomized clinical trial of participant satisfaction with three types of mandibular implant-retained overdentures. J Dent Res 2004;83:630-633.

20. Feine JS, Maskawi K, de Grandmont P, Donohue WB, Tanguay R, Lund JP. Within-subject comparisons of implant-supported mandibular prostheses: Evaluation of masticatory function. J Dent Res 1994;73:1646-1656.

21. Geertman ME, Slagter AP, van 't Hof MA, van Waas MA, Kalk W. Masticatory performance and chewing experience with implantretained mandibular overdentures. J Oral Rehabil 1999;26:7-13.

22. Feine JS, de Grandmont P, Boudrias P, et al. Within-subject comparisons of implant-supported mandibular prostheses: Choice of prosthesis. J Dent Res 1994;73:1105-1111.

23. Tang L, Lund JP, Taché R, Clokie CM, Feine JS. A within-subject comparison of mandibular long-bar and hybrid implant-supported prostheses: Psychometric evaluation and patient preference. J Dent Res 1997;76:1675-1683. 
24. de Grandmont P, Feine JS, Taché R, et al. Within-subject comparisons of implant-supported mandibular prostheses: Psychometric evaluation. J Dent Res 1994;73:1096-1104.

25. Attard NJ, Zarb GA, Laporte A. Long-term treatment costs associated with implant-supported mandibular prostheses in edentulous patients. Int J Prosthodont 2005;18:117-123.

26. Attard N, Wei X, Laporte A, Zarb GA, Ungar WJ. A cost minimization analysis of implant treatment in mandibular edentulous patients. Int J Prosthodont 2003;16:271-276.

27. Palmqvist $\mathrm{S}$, Owall B, Schou S. A prospective randomized clinical study comparing implant-supported fixed prostheses and overdentures in the edentulous mandible: Prosthodontic production time and costs. Int J Prosthodont 2004;17:231-235.

28. Fitzpatrick B. Standard of care for the edentulous mandible: A systematic review. J Prosthet Dent 2006;95:71-78.

29. van Kampen FM, van der Bilt A, Cune MS, Fontijn-Tekamp FA, Bosman F. Masticatory function with implant-supported overdentures. J Dent Res 2004;83:708-711.

30. van Kampen FM, van der Bilt A, Cune MS, Bosman F. The influence of various attachment types in mandibular implant-retained overdentures on maximum bite force and EMG. J Dent Res 2002; 81:170-173.

31. van Kampen F, Cune M, van der Bilt A, Bosman F. Retention and postinsertion maintenance of bar-clip, ball, and magnet attachments in mandibular implant overdenture treatment: An in vivo comparison after 3 months of function. Clin Oral Implants Res 2003;14:720-726.

32. Cune M, van Kampen F, van der Bilt A, Bosman F. Patient satisfaction and preference with magnet, bar-clip, and ball-socket retained mandibular implant overdentures: A cross-over clinical trial. Int J Prosthodont 2005;18:99-105.

33. Stellingsma K, Bouma J, Stegenga B, Meijer HJ, Raghoebar GM. Satisfaction and psychosocial aspects of patients with an extremely resorbed mandible treated with implant-retained overdentures. A prospective, comparative study. Clin Oral Implants Res 2003;14:166-172.

34. Cune MS, Verhoeven JW, Meijer GJ. A prospective evaluation of Frialoc implants with ball-abutments in the edentulous mandible: 1-year results. Clin Oral Implants Res 2004;15:167-173.

35. Cune MS, van Rossen IP, de Putter C, Wils RP. A clinical retrospective evaluation of FA/HA coated (Biocomp) dental implants. Results after 1 year. Clin Oral Implants Res 1996;7:345-353.

36. van Kampen F, Cune M, van der Bilt A, Bosman F. The effect of maximum bite force on marginal bone loss in mandibular overdenture treatment: An in vivo study. Clin Oral Implants Res 2005; 16:587-593.

37. Carlsson GE, Kronström M, de Baat $\mathrm{C}$, et al. A survey of the use of mandibular implant overdentures in 10 countries. Int J Prosthodont 2004:17:211-217.

38. Cune MS, de Putter C, Hoogstraten J. A nationwide evaluative study on implant-retained overdentures. J Dent 1997;25(suppl 1): S13-S19.

39. Bakke M, Holm B, Gotfredsen K. Masticatory function and patient satisfaction with implant-supported mandibular overdentures: A prospective 5-year study. Int J Prosthodont 2002;15:575-581.

40. Zarb GA, Schmitt A. The edentulous predicament. II: The longitudinal effectiveness of implant-supported overdentures. J Am Dent Assoc 1996;127:66-72.

41. Naert I, Alsaadi G, Quirynen M. Prosthetic aspects and patient satisfaction with two-implant-retained mandibular overdentures: A 10year randomized clinical study. Int J Prosthodont 2004;17:401-410.
42. Stoker GT, Wismeijer D, van Waas MA. An eight-year follow-up to a randomized clinical trial of aftercare and cost-analysis with three types of mandibular implant-retained overdentures. J Dent Res 2007;86:276-280.

43. Davis DM, Packer ME. The maintenance requirements of mandibular overdentures stabilized by Astra Tech implants using three different attachment mechanisms-Balls, magnets, and bars; 3-year results. Eur J Prosthodont Restor Dent 2000;8:131-134.

44. MacEntee MI, Walton JN, Glick N. A clinical trial of patient satisfaction and prosthodontic needs with ball and bar attachments for implant-retained complete overdentures: Three-year results. J Prosthet Dent 2005;93:28-37.

45. Walton JN. A randomized clinical trial comparing two mandibular implant overdenture designs: 3-year prosthetic outcomes using a six-field protocol. Int J Prosthodont 2003;16:255-260.

46. Gotfredsen K, Holm B. Implant-supported mandibular overdentures retained with ball or bar attachments: $A$ randomized prospective 5-year study. Int J Prosthodont 2000;13:125-130.

47. Dudic A, Mericske-Stern R. Retention mechanisms and prosthetic complications of implant-supported mandibular overdentures: Long-term results. Clin Implant Dent Relat Res 2002;4:212-219.

48. Kleis WK, Kämmerer PW, Hartmann S, Al-Nawas B, Wagner W. A comparison of three different attachment systems for mandibular two-implant overdentures: One-year report. Clin Implant Dent Relat Res 31 March 2009 [epub ahead of print].

49. Visser A, Meijer HJ, Raghoebar GM, Vissink A. Implant-retained mandibular overdentures versus conventional dentures: 10 years of care and aftercare. Int J Prosthodont 2006;19:271-278.

50. Payne AG, Solomons YF. The prosthodontic maintenance requirements of mandibular mucosa- and implant-supported overdentures: A review of the literature. Int J Prosthodont 2000;13:238-243.

51. Payne AG, Walton TR, Walton JN, Solomons YF. The outcome of implant overdentures from a prosthodontic perspective: Proposal for a classification protocol. Int J Prosthodont 2001;14:27-32.

52. Watson RM, Jemt T, Chai J, et al. Prosthodontic treatment, patient response, and the need for maintenance of complete implant-supported overdentures: An appraisal of 5 years of prospective study. Int J Prosthodont 1997;10:345-354.

53. Verhoeven JW, Cune MS, de Putter C. Reliability of some clinical parameters of evaluation in implant dentistry. J Oral Rehabil 2000; 27:211-216.

54. Salvi GE, Lang NP. Diagnostic parameters for monitoring peri-implant conditions. Int J Oral Maxillofac Implants 2004;19(suppl): 116-127.

55. Lang NP, Berglundh T, Heitz-Mayfield LJ, Pjetursson BE, Salvi GE, Sanz M. Consensus statements and recommended clinical procedures regarding implant survival and complications. Int J Oral Maxillofac Implants 2004;19(suppl):150-154.

56. Lang NP, Wilson TG, Corbet EF. Biological complications with dental implants: Their prevention, diagnosis and treatment. Clin Oral Implants Res 2000;11(suppl 1):146-155.

57. Naert I, Alsaadi G, van Steenberghe D, Quirynen M. A 10-year randomized clinical trial on the influence of splinted and unsplinted oral implants retaining mandibular overdentures: Peri-implant outcome. Int J Oral Maxillofac Implants 2004;19:695-702.

58. Oetterli M, Kiener P, Mericske-Stern R. A longitudinal study on mandibular implants supporting an overdenture: The influence of retention mechanism and anatomic-prosthetic variables on periimplant parameters. Int J Prosthodont 2001;14:536-542. 